\title{
The additive advantage of having educated grandfathers for children's education: evidence from a cross-national sample in Europe
}

\author{
Working paper presented at the Multi-generational social mobility workshop \\ Nuffield College, 21722 September 2017 - Version December 2017
}

\author{
Paula Sheppard* \\ Christiaan Monden \\ *corresponding author: \\ Department of sociology \\ University of Oxford \\ Manor Road, Oxford, OX1 3UQ, United Kingdom \\ paula.sheppard@sociology.ox.ac.uk
}

\begin{abstract}
Until recently, research on intergenerational processes of social mobility has focused on two generational processes and paid little attention to the role of the grand-parental generation. An increasing number of studies have started to address this shortfall, but they report inconsistent findings. This may be due to design and measurement differences across studies and to substantive heterogeneity in the association. We use data from the Survey of Health, Ageing, and Retirement in Europe (SHARE) to explore these two issues. First, as we have information on all four grandparents, and both parents, we were able to evaluate the different ways to model grandparental associations. We found that including information on both grandfathers provided the best fit, once controlling for parental education. Second, we investigated the moderating effects of parental education, family size, and the grandparents' being alive during the grandchild's early life and school years. Having higher educated grandfathers is associated with higher educational outcomes for grandchildren, net of parental education and wealth. Moreover, having two highly educated grandfathers shows a stronger association than just one. We found no evidence for the interactions we tested making it unclear what the mechanisms underlying the association are. Future work to identify the mechanisms may be able to shed light on the actual role that grandparents play.
\end{abstract}

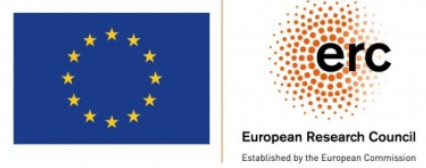

This research has received funding from the European Research Council (ERC) under the European Union's Horizon 2020 research and innovation programme under grant agreement No 681546 (FAMSIZEMATTERS) 


\section{Introduction}

Research on intergenerational processes of social mobility has a long history but has until recently tended to focus only on two generations: parent and child. A large body of evidence for this association has established that parents' education is a strong predictor of the child's educational achievements. Logically then the parent's education is also influenced by his or her own parent's (i.e. the grandparent's) education. The intergenerational impact of grandparents on a grandchild's academic success remains to be explored. In particular, the question is whether the association between grandparents and grandchildren is wholly mediated by the interim generation, as in a Markovian process, or whether an association remains, independently of parents' achievements. If this is the case, then past research will have not only overestimated the effect of parent-to-child educational endowment, as some of it will be due to earlier generations' influence, but also underestimated the importance of family background as a whole.

There is growing interest in the association between grandparental and even greatgrandparental socioeconomic position and educational outcomes of their offspring (Mare 2011; Braun \& Stuhler 2016; Pfeffer 2014). Recent studies have begun to extend our knowledge of these associations and potential underlying processes by including information on the socioeconomic status of grandparents and great-grandparents in their analyses. The findings so far have, however, been mixed, with some suggesting independent associations of grandparental social class or education with grandchildren's outcomes after taking into account the socioeconomic status of the parents (Chan \& Boliver 2013; Knigge 2016; Ferrie et al. 2016; Møllegaard \& Jæger 2015; Deindl \& Tieben 2016; Lindahl et al. 2012; Hällsten \& Pfeffer 2016; Modin et al. 2013; Ziefle 2016), while others find no evidence for such associations (Warren \& Hauser 1997; Wolbers \& Ultee 2013; Erola \& Moisio 2007; Bol \& Kalmijn 2016).

There are a number of possible explanations for these mixed findings. They may simply reflect true heterogeneity in the association across time and place or by other contextual characteristics of the samples. The existence of strong moderators, who are often not modelled but whose distribution may vary across societies, time and samples, may contribute to mixed findings in associations averaged over the population. Mixed findings may also result from differences in statistical modelling techniques, measurement of core concepts, 
and/or study design (including the richness of the data). In particular, many studies only have information on one set of grandparents (i.e. only the paternal or maternal side) or even just one parent. It is difficult, if not impossible, to properly assess the nature of grandparent and grandchild socioeconomic associations without full information on the three generations.

Exploiting features of the Survey of Health, Ageing, and Retirement in Europe (SHARE) we make two contributions to the literature. First, we use information about the educational attainment of all four grandparents and both parents. Combined with the large sample size of SHARE, this allows us to explore the relative value of different ways to model grandparental education in three-generational associations and to address questions about gender- and lineage-specific associations. Our second contribution lies in exploring three potentially important moderators of the association between grandparental education and grandchildren's educational outcomes. The average association only tells part of the story if important moderators exist, even in a model that takes into account all grandparents and parents. Moreover, testing for moderators also sheds some light on the plausibility of possible mechanisms that explain the association.

Several moderators have been suggested in the literature. Parents' socio-economic position and measures of grandparental contact or availability are the two most common moderators in this growing literature (Anderson et al. 2018). First, the influence of grandparents may be moderated by the parents' level of education, for example where highly-educated grandparents compensate for less well educated parents (Pfeffer 2014). Second, some explanations of the association between grandparents' and grandchild education require close interaction between the grandparent and grandchild, during the grandchild's childhood (Knigge 2016). While data on actual contact time during childhood are hard to come by, we can draw indirect inference based on the overlap between the grandparent's lifespan and grandchild's early life. We argue that family size may be another important moderator. Applying the notion of resource dilution (Blake 1986; Gibbs et al. 2016) to grandparental resources merits examining family size in light of the substantial variation of fertility within and between populations and over time. Grandchildren with fewer siblings and fewer cousins may benefit more from their grandparents' socioeconomic position compared to grandchildren who have to share that same amount of resources with more siblings and cousins. SHARE provides measures to examine these three moderators: parental education, generational overlap, and family size. 
In sum, we aim to answer the following three research questions:

1. How do different ways of modelling grandparental education compare to each other in terms of model fit? In other words, what is the best way to operationalise "grandparental education" when information about all four grandparents is available?

2. To what extent is grandparental education associated with grandchildren's education independent of parents' education, and parental wealth?

3. To what extent is the association between grandparental education and grandchildren's education moderated by a) the educational level of the parents, b) overlapping lifespans of grandparents and grandchildren, and c) family size?

\section{Background and hypotheses}

Before we discuss possible mechanisms linking grandparental education directly to that of their grandchildren, we have to acknowledge that part of the debate is whether there is any direct association at all. Studies that assert to have found evidence for such associations, often do not have detailed information about the education and socioeconomic position of the parental family. We refer hereon to grandparents as G1 (Generation 1), parents as G2, and grandchildren as G3. It is possible that the G1-G3 association is due to the relatively poor measurement of parental (G2) characteristics. In other words, the process is in reality Markovian, but direct associations are still observed because of limited measurement of G2. The empirical findings in studies by for instance Warren \& Hauser (1997), Bol \& Kalmijn (2016), Wolbers \& Ultee (2013) are in line with such an interpretation. However, we also have to be careful in interpreting the absence of a direct G1-G3 association. It can be the result of heterogeneity in the G1-G3 association (i.e. meaningful conditional G1-G3 associations go unnoticed when only the average G1-G3 association is estimated). Finally, in some cases, the absence of a statistically significant G1-G3 association may also be due small sample sizes if true effect sizes are small.

\section{Measuring grandparental education}

Intuitively it seems obvious what is meant by "grandparental education”. There is considerable variation, however, in how it is treated empirically. Most research ignores the fact that children have four grandparents - maternal and paternal grandparents. Where data on more than one grandparent are available, the highest educated grandparent is often chosen 
to represent the whole generation (e.g. Deindl \& Tieben 2016; Møllegaard \& Jæger 2015; Ziefle 2016) - this is known as the dominance approach in the status attainment literature. This method is potentially problematic because it ignores between-family differences. Families with, for example, one highly educated grandparent may be different to families with two, three, or four highly educated grandparents, especially if intergenerational educational correlations are understood in terms of a pro-educational 'family culture'. Furthermore, we cannot identify which grandparent is the 'dominant' one thereby losing any nuanced interpretation of the importance of a particular lineage or gender of grandparents. While there is no strong theoretical reason to expect that maternal and paternal grandparents exert different influences on grandchild outcomes, it is arguable that paternal grandparents might be more important in patrilineal contexts, if the mechanisms are to do with inheritance (although this would only benefit the male children and grandchildren). The anthropological literature, on the other hand, suggests that maternal grandparents are more important in general for children than paternal grandparents (due partly to paternity confidence limits) (Coall et al. 2014; Sear et al. 2000). In Europe, we might still expect maternal grandparents to be more important because if the G2 union breaks down, the mother, who usually retains guardianship of the children, can rely on her own parents rather than her parents-in-law.

In other cases, depending on which parent was interviewed, one of the two grandfathers is simply used as the representative of grandparental education. In practice this will often be similar to the dominance approach as, until recently, grandfathers were more likely to be more highly educated than grandmothers, but the gender gap in higher education is changing rapidly (Klesment \& Van Bavel 2015) making this approach increasingly less valid. Data limitations often make it impossible to differentiate between different grandparents or parents, but to advance our understanding of the G1-G3 association, information on all members of G1 and G2 is needed. Here we investigate the consequences of different approaches directly by exploiting information on the educational level of each individual grandparent and parent. We take an explorative empirical approach to the question of how to operationalise "grandparental education” by testing different ways it can be and has been measured in the literature.

\section{Possible mechanisms for a direct G1-G3 association}

There is ongoing debate about the possible mechanisms that explain the association between grandparents' education and grandchildren's education (or socioeconomic outcomes more 
broadly) (Knigge 2016; Mare 2014; Bol \& Kalmijn 2016). The proposed mechanisms can be broadly grouped as cultural or material mechanisms. Additionally, some mechanisms require actual interactions between grandparents and grandchildren, whereas others do not. We sketch these main mechanisms only briefly. Our aim is not to provide a comprehensive overview, but rather to provide the context for our hypotheses about the moderating effects of parental education, family size, and generational overlap.

\section{Cultural mechanisms}

Cultural mechanisms refer to the role grandparents play in shaping grandchildren's attitudes, aspirations, and actual knowledge or academic achievements by means of their own attitudes or knowledge. This includes, for instance, grandparents reading to grandchildren or helping with homework, but also grandparents fostering expectations about educational attainment and passing on relevant cultural knowledge (see for instance Møllegaard and Jæger (2015)). Various concepts have been suggested to capture the idea of pro-educational family environments that stretch over more than two generations: dynastic capital (Lindahl et al. 2015), cumulative cultural advantage (Ziefle 2016), and cultural capital in various forms e.g. Møllegaard and Jæger (2015). Although most studies cannot measure cultural mechanisms directly, most cultural mechanisms have in common that they require physical interaction (contact and/or communication) between the generations. Møllegaard and Jæger (2015), for example, report that in Denmark grandparental cultural capital as measured by education, newspaper subscription, and participation in classes, was positively associated with grandchildren choosing an academic pathway in secondary school after controlling for G1 economic and social capital and G2 cultural, economic and social capital. In the context of a relatively economically egalitarian setting, these findings support the idea that the family's cultural environment rather than tangible material support is important for educational outcomes. In post demographic transition contexts with ageing populations where people are living longer and healthier lives, grandparents have increasing opportunities for meaningful interactions with their grandchildren (Carr et al. 2003).

\section{Material mechanisms}

Grandparents can also facilitate their grandchildren's educational attainment by material means, such as paying for school and college or university fees (including accommodation and maintenance costs), tutoring and remedial teaching, extra-curricular activities, and offsetting opportunity costs or buffering the risk of taking on college debt. These various 
pathways have been grouped together as purchasing mechanisms and insurance mechanisms by Hällsten and Pfeffer (2016) to explain how grandparental wealth can affect grandchildren's educational attainment. There is evidence for an association between parental and grandparental wealth on the one hand and grandchildren's education on the other hand, even in relatively egalitarian countries like Sweden (Hällsten \& Pfeffer 2016; Pfeffer 2014).

Moderators

\section{Parental education as moderator}

Are grandparents equally important for grandchildren across different levels of parental education? For sociologists analysing this question this is perhaps the most natural next step in the analysis as the interaction between G1 and G2 reflects a core sociological interest: social mobility. Do grandparents especially compensate for downward mobility of the second generation, or do they strengthen the advantage bestowed on children by higher-educated parents? Such questions have been addressed elaborately with regard to social class (Chan \& Boliver 2013; Erola \& Moisio 2007; Hertel \& Groh-Samberg 2014; Warren \& Hauser 1997) but also educational attainment (Fuchs \& Sixt 2007; Jæger 2012; Pfeffer 2014; Ziefle 2016). A number of studies have reported evidence for interactions, but here again, empirical results are mixed. Stronger grandparental effects have been found among parents with a lower education or occupational status (Jæger 2012; Wightman \& Danziger 2014), but also among the highest parental group only (Lindahl et al. 2012; Chiang \& Park 2015), and yet others have suggested that multigenerational associations might be strongest at the extremes of the socio-economic distribution (Pfeffer 2014; Mare 2011). We examine the interactions and test whether there are stronger associations between G1 and G3 education when the middle generation has less education, or when the parents are also highly educated.

\section{Lifespan overlap as a moderator}

Some of the mechanisms that have been proposed in the literature require direct contact between grandparents and grandchildren. Knigge (2016), for instance, referred to “contact mechanisms" when talking about the transfer of resources through socialization. This involves most, if perhaps not all, cultural pathways where grandparents affect grandchildren independently of the parents. For other mechanisms, such as grandparental wealth, direct contact is not strictly required; Knigge referred to these as “durable resource mechanisms”. If we are interested in the influences of grandparents that are not mediated through the parental 
generation, we would expect that for mechanisms that require contact, then this would strengthen the influence of grandparents. We propose to examine this general hypothesis by comparing G1-G3 associations between grandchild-grandparent dyads with overlapping lifespans of at least 5,10 or 16 years.

\section{Family size as a moderator}

Several mechanisms in the literature concern finite resources that grandparents can use to help their grandchildren, such as money and other material resources as well as time. The finite character of such grandparental resources makes family size a potential source of heterogeneity in the G1-G3 association. In other words, resource dilution may mean that the degree to which grandparents influence their grandchildren depends on the number of grandchildren. The resource dilution argument has originally been made for parental resources and educational attainment of children, positing that where limited parental resources have to divided among more siblings each child receives less (Blake 1986). There is a substantial literature on the correlation between sibship size and socioeconomic outcomes (see for instance Gibbs et al. (2016)) While a negative association is found across high income countries and across birth cohorts (Choi et al. 2017), there is debate to what extent this association reflects a causal effect of sibship size and to what extent it reflects selective fertility (Black et al. 2005; Steelman et al. 2002; Angrist et al. 2010).

With regard to grandparents, the dilution idea can be applied to those mechanisms that involve direct and intense contact (i.e. time investment) and finite material resources (i.e. wealth). We argue that resource dilution thus may play a role in several plausible pathways. Some other mechanisms, such setting of a norm, or expectations about education, might be much less affected by the number of grandchildren. Whereas the number of grandchildren clearly makes a difference when assisting with school fees or tutoring, setting an example, for instance, for ten rather than five grandchildren might not cost more time or effort on the grandparent's side. Still, grandchildren also compete with their siblings and their cousins for time and attention from grandparents. To the extent that the benefits a higher educated grandparents compared to a lower educated one can bring a grandchild are constrained by finite resources, we should expect resource dilution. Following this reasoning, we expect grandparental education to be more beneficial for children (G3) with fewer siblings and fewer cousins. Therefore, we examine to what extent the positive association between grandparental 
education and grandchild's education is moderated by family size measured at both G3 (siblings) and G2 (potential number of cousins).

\section{Methods}

Data

The Survey of Health, Ageing, and Retirement in Europe (SHARE) is an ongoing interdisciplinary, longitudinal survey in Europe. Data were collected over six waves from 2004 to 2015 from a representative sample of over 50-year-olds from 21 countries across Europe, and Israel. All household members over the age of 50 were interviewed as well as spouses who were younger than 50. The SHARE data and documentation can be found at www.share-project.org and Börsch-Supan et al. (2013) provide a detailed profile of the SHARE surveys. The respondents in SHARE form our middle generation G2 (parents). This generation reports on the educational outcomes of G3, their children, and G1, their own parents (the grandparents of G3). In waves 1 and 2, information for up to four of the respondents' children was collected, in later waves information was recorded for all the children. We used information from waves 1, 2, 4, 5 and 6 to maximise the number of cases for which we have information on all three generations (wave 3 had a different format and could not be included here). Information about grandparents' education was first asked in wave 5. We include all respondents who joined SHARE in wave 5 or 6 as well as respondents who started in earlier waves if they were interviewed in wave 5 or 6 . This latter group provided information about their children (G3) in waves 1 , 2 or 4, and information about their parents (G1) in waves 5 or 6 . Newly sampled respondents in wave 5 and 6 provide all necessary information in one single interview. We had to exclude data from Poland, Ireland, Greece, Hungary, Croatia, and Portugal, where there was no (valid) information on G1. Our analytic sample contains data from fifteen countries: Austria, Belgium, Czechia, Denmark, Estonia, France, Germany, Israel, Italy, Luxembourg, the Netherlands, Slovenia, Spain, Sweden, and Switzerland.

Linking couples (G2) in households, their parents (G1), and their children (G3), gives a final analytical sample of 35,280 children nested in 16,129 families. Specifically, we started with 75,996 respondents who were interviewed in waves 5 and 6, and 68,825 of those provided valid information on G1 education. To have information on all four grandparents, we could only use data from couples (G2) where both members of the couple were interviewed; 
removing individuals from households where only one respondent was interviewed, left 21,368 couples, excluding 11,024 couples where only one of the partners participated. These incomplete cases with only one responding partner have slightly higher educational attainment in generations 1 and 2 and a similar number of children compared to complete cases (see supplementary table S1). We removed 40 same sex couples (unlikely to have raised their children together). The full sample selection process is shown in supplementary table S2.

SHARE data were collected for only four children in the first two waves, and then for all children from wave 4 onward. These children are not always the same children; i.e. child number 1 in wave 1 might be child number 3 in wave 4 and a different child labelled as child number 1 . In cases where the child's year of birth and gender do not match across waves could be because of children being reassigned child numbers, or because of new blended families, or from data-entry errors. We have no way to discern which it is for each child and so we removed children who did not match in year of birth and gender over waves. We started with those 42,552 children (G3) for whom a valid response for education was recorded. We removed children who were mismatched in sex and birth year across waves, and those who were not yet 23 years old at the time of survey as they might not have had the chance to go to university (9,316 altogether) We dropped a further 10 children who were implausibly listed as being born before 1935. Cases with missing values on parental education were also removed (leaving 36,503 children). These independent variables could be imputed, but our first step in the analysis - model fit comparisons with AIC - cannot be performed in a multiple imputation setup. We lose 1,223 observations to missing data here but multiply imputed values for seven other variables (if each grandfather was alive, year of each grandfather's death, mother was an only child, father was an only child, net household wealth) were included in later models (using Stata’s multiple imputation module mi).

\section{Variables}

Educational levels for all three generations were recorded in the International Standard Classification of Education (ISCED) scale to enable cross-national comparisons (UNESCO 2013). All waves have education variables in the ISCED 1997 6-level scale (converted from the 2011 ISCED for waves 5 and 6). We recoded education into four levels for grandparents and parents: up to primary school (including those who report no education), lower secondary, higher secondary, and post-secondary education including 'non-tertiary post- 
secondary’ (ISCED level 4) and short-cycle tertiary (see table S3). We use this upper category, which includes more post-secondary education than actual tertiary, because most grandparents (G1) in our sample lived during a time when very few people, especially women, went on to tertiary education. We report sensitivity analyses using a countrystandardised z-score based on the ISCED scale (for all three generations), and another set of models using a lower/post-secondary education dichotomy, in tables S4 and S5. Educational attainment for G3 was constructed as a binary variable denoting whether or not the child had attained tertiary education (ISCED Level 5 or higher). About three quarters of the third generation in our sample are born between 1965 and 1985. For this generation obtaining at tertiary degree is suitable marker of higher education.

Small family size was defined as having one or two children in the third generation (G3). By this measure $47 \%$ of the children in our sample come from 'small' families. We constructed a second variable of sibship size (to use as a robustness check) divided as follows: child is an only child (9\%), child has 1 sibling (38\%), 2 siblings (27\%), or 3+ siblings (26\%). For parents (G2), we only have information of the surviving siblings, and given that this is a sample of over-50-year-olds, this variable would not be an accurate indicator of number of cousins of G3. Rather we use two binary variables denoting whether father or mother (G2) was an only child (around 10\% and 9\% respectively).

Generational overlap is captured separately for each grandchild-grandparent dyad by a binary variable for whether the grandparent was alive until at least the grandchild's $16^{\text {th }}$ year. For robustness checks, we also coded this variable with cut-offs of age 5 and 10 . Note that here we do not use the number of educated grandfathers a child has, but include education separately for each grandfather. To capture socioeconomic resources other than education we included household net wealth of G2. We use the net wealth variable generated by SHARE survey administrators (SHARE 2015). Because of missing data in the many variables necessary to construct household net wealth, this variable is provided as a set of five imputed values. We standardised household net wealth by country to make it cross-nationally comparable. We further controlled for child gender (49\% female) and child year of birth (mean 1974, s.d. 9).

\section{Analytical Strategy}


We used linear probability models to estimate the probability of a G3 child attaining a tertiary education (Mood 2010; Hellevik 2009). Our models contain country fixed-effects and random-effects to account for nesting of grandchildren (G3) within parents (G2) (using xtmixed in Stata v. 14). Because SHARE samples are not proportional to the size of the countries' population, we weighted all regression analyses to account for differences in sample-to-population ratios (unweighted analyses gave the same results).

For our first research question, we compare models with different ways of operationalising grandparental education. With four grandparents and many ways to count and weight each grandparent's educational attainment, we face a large number of possible operationalisations of 'grandparental education'. Guided by what previous studies use, and by theoretical considerations (e.g. where lineages might be important) we defined G1 education in the following 14 ways:

a) Educational level of all four individual grandparents (4 variables with 4 levels each)

b) Educational level of each grandfather ( 2 x 4 levels)

c) Educational level of paternal grandfather only (1 x 4 levels)

d) Educational level of maternal grandfather only (1 x 4 levels)

e) Number of post-secondary educated grandparents (1 variable; $0-4)$

f) Number of paternal and maternal post-secondary educated grandparents (2 variables; $0,1$ or 2$)$

g) Number of post-secondary educated grandfathers and grandmothers (2 variables; 0,1 or 2)

h) Number of post-secondary educated grandfathers (1 variable; 0,1 , or 2 )

i) Educational level of a single dominant grandparent (1 x 4 levels)

j) Educational level of dominant maternal and dominant paternal grandparent ( 2 x 4 levels)

k) Educational level of dominant grandfather and dominant grandmother ( 2 x 4 levels)

l) Average level of all grandparents (1 variable)

m) Average level of maternal and average level of paternal education (2 variables)

n) Average level of grandfathers' and average level of grandmothers' education (2 variables) 
Dominant in models ( $\mathrm{i}, \mathrm{j}$, and $\mathrm{k}$ ) refers to the grandparent with the highest educational attainment (e.g. “dominant grandmother” in model k refers to the highest educational level of the two grandmothers). All models (a-n) control for grandchildren's gender and year of birth. Because models a-n are not nested, we use the Akaike Information Criterion (AIC) to compare relative model fit.

After determining how to model grandparental education, we addressed our second and third research questions with a sequence of models. First, model I included only the two grandfathers' education and control variables. We then added the father's education to test if any grandparental associations remained (model II) and then we included the mother's education (model III). Finally, we added a variable to adjust for G2 household net wealth (model IV). To test whether grandparental effects were moderated we added interactions oneby-one for: G2 and G3 family size (models VI-IX), parent's education (models X and XI), and grandparent lifespan overlapping with grandchild early childhood and school years (models XII-XIV).

\section{Results}

\section{G1-G2-G3 correlations}

Table 1 shows correlations between G1, G2 and G3 education. The pattern is as expected: higher correlations within generations and lower correlations between generations with the G1-G3 correlation clearly lower than those between G2-G1 and G2-G3. These correlations seem consistent with a Markovian model. For the paternal line (fathers and grandfathers) the G1-G2 and G2-G3 correlations of 0.47 and 0.38, respectively, lead to an expected G1-G3 correlation of 0.17 for G1-G3, which is very close to the observed correlation of 0.19 . Table 2a shows the distribution of G1 and G2 education, and table $2 \mathrm{~b}$ shows the distribution of G1 and G2 education by grandchild's education; $41 \%(14,638)$ of all grandchildren attained a tertiary education. We observe the familiar pattern of a higher proportion of grandchildren obtaining tertiary education the higher the educational attainment of G1 or G2. The gradient is steeper for G2 than for G1; i.e. the percentage of grandchildren (G3) with tertiary education increases from about 20\% among the lowest educated parents to $65 \%$ among the highest educated parents, whereas the comparable figures are about $38 \%$ to $62 \%$ for grandparents. 
Table 1: Pearson correlations between family member's educational levels.

\begin{tabular}{|c|c|c|c|c|c|c|}
\hline & Paternal GF & $\begin{array}{c}\text { Paternal } \\
\text { GM }\end{array}$ & $\begin{array}{c}\text { Maternal } \\
\text { GF }\end{array}$ & $\begin{array}{c}\text { Maternal } \\
\text { GM }\end{array}$ & Father & Mother \\
\hline Paternal GF & 1 & & & & & \\
\hline Paternal GM & 0.66 & 1 & & & & \\
\hline Maternal GF & 0.51 & 0.49 & 1 & & & \\
\hline Maternal GM & 0.47 & 0.50 & 0.65 & 1 & & \\
\hline Father & 0.47 & 0.42 & 0.43 & 0.40 & 1 & \\
\hline Mother & 0.39 & 0.38 & 0.45 & 0.45 & 0.58 & 1 \\
\hline Grandchild & 0.19 & 0.18 & 0.20 & 0.18 & 0.38 & 0.37 \\
\hline
\end{tabular}

GF = grandfather, $G M=$ grandmother

Education is measured on the 1-6 ISCED 1997 scale.

Table 2a: Distribution of grandparents' (G1) and parents' (G2) education, $n$ (row \%)

\begin{tabular}{|lllll|}
\hline & Up to primary & $\begin{array}{l}\text { Lower } \\
\text { secondary }\end{array}$ & $\begin{array}{l}\text { Higher } \\
\text { secondary }\end{array}$ & $\begin{array}{l}\text { Post- } \\
\text { secondary }\end{array}$ \\
\hline Paternal grandfather & $17,058(48)$ & $5,543(16)$ & $8,926(25)$ & $3,753(11)$ \\
Maternal grandfather & $16,723(47)$ & $5,654(16)$ & $9,111(26)$ & $3,792(11)$ \\
Paternal grandmother & $19,804(56)$ & $8,670(25)$ & $5,176(15)$ & $1,630(5)$ \\
Maternal grandmother & $18,830(53)$ & $8,610(24)$ & $5,815(16)$ & $2,025(6)$ \\
Father & $6,572(19)$ & $5,943(17)$ & $12,472(35)$ & $10,293(29)$ \\
Mother & $7,397(21)$ & $6,940(20)$ & $11,763(33)$ & $9,180(26)$ \\
\hline
\end{tabular}

Table 2b: Percentage of grandchildren (G3) who attained tertiary education by grandparental (G1) and parental education (G2)

\begin{tabular}{|lllll|}
\hline & Up to primary & $\begin{array}{l}\text { Lower } \\
\text { secondary }\end{array}$ & $\begin{array}{l}\text { Higher } \\
\text { secondary }\end{array}$ & $\begin{array}{l}\text { Post- } \\
\text { secondary }\end{array}$ \\
\hline Paternal grandfather & $38 \%$ & $38 \%$ & $43 \%$ & $61 \%$ \\
Maternal grandfather & $37 \%$ & $40 \%$ & $43 \%$ & $61 \%$ \\
Paternal grandmother & $39 \%$ & $39 \%$ & $49 \%$ & $64 \%$ \\
Maternal grandmother & $39 \%$ & $39 \%$ & $48 \%$ & $62 \%$ \\
Father & $23 \%$ & $29 \%$ & $38 \%$ & $65 \%$ \\
Mother & $22 \%$ & $30 \%$ & $42 \%$ & $65 \%$ \\
\hline
\end{tabular}

Main model for grandparental education

Table 3 shows the AIC model fit statistics for each of the fourteen models operationalising

G1 educational attainment. Column one gives the model numbers in the order of AIC scores.

Column four gives a summary of any evidence for an independent grandparent/grandchild association in each model, based on the model coefficients and their standard errors. Our first observation is that the difference in model fit is modest; there are just over 15 points difference between the highest and lowest scores. The lowest AIC statistic was obtained for model h, i.e. the highest number of post-secondary educated grandfathers. We therefore 
proceeded with all further analyses using the number of post-secondary educated grandfathers as our G1 specification.

As a robustness check, we also ran country-level standardised versions of the ISCED 1997 levels where people were assigned z-scores for how far above or below the country mean their educational level was (for all three generations). These show very much the same results with only grandfathers being important (and in all cases significant results net of parental education), although the model with the average of grandparental education best fits the data. These results are provided in the supplement (table S6). Standardised variables are rather tricky to substantively interpret and so we retained the four-category education variable for the rest of the study, and a binary outcome for child education. Finally, we also executed the fourteen models separately for each country to investigate if there are country differences in which model best fits the data. The best fitting model differs across countries with no clear patterns as to the best fit, nor with regard to the main findings from the coefficients and pvalues. The only consistent finding across models is that, where there is an association, it tends to be for highly educated grandfathers and there is little evidence for an influence of grandmothers in any country (discussed more below).

Table 3: Model fit and summarised effects of grandparental education for different operationalisations of grandparental education.

\begin{tabular}{|l|l|l|l|}
\hline Model & Operationalisation of grandparent education & AIC & $\begin{array}{l}\text { Significant G1-G3 } \\
\text { Association?* }\end{array}$ \\
\hline h & Number of post-sec educated grandfathers only & 34277.6 & Yes, highest for 2 \\
n & Grandfather average and grandmother average & 34281.37 & Grandfathers only \\
g & Number of post-sec educated grandmothers and grandfathers & 34281.45 & Grandfathers only \\
i & Single dominant grandparent & 34281.59 & Post-sec only \\
l & Average of all grandparental education & 34281.96 & Yes \\
b & Both individual grandfathers & 34281.97 & Yes, post-sec \\
f & Number of paternal and maternal post-sec educated GPs & 34282.81 & Yes \\
e & Number of post-secondary educated grandparents & 34283.35 & 1, 2, or 3 vs 0 \\
m & Maternal average and paternal average & 34283.59 & Paternal \\
j & Dominant maternal and paternal grandparents & 34284.33 & Post-sec of both \\
c & Paternal grandfather only & 34285.18 & Yes, post-sec only \\
k & Dominant grandfather and dominant grandmother & 34286.41 & Post-sec \\
d & Maternal grandfather only & 34287.95 & Yes, post-sec only \\
a & All four individual grandparents & 34293.03 & GFs post-sec only \\
\hline \multicolumn{2}{|l}{ N=35,280 children (16,129 families) } \\
*all positive associations & All models control for both parent's education, country, and grandchild age and gender
\end{tabular}


Table 4: Estimates from linear probability models for four primary models.

\begin{tabular}{|c|c|c|c|c|c|c|c|c|}
\hline 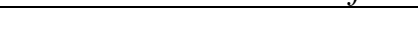 & \multicolumn{2}{|c|}{ Model I } & \multicolumn{2}{|c|}{ Model II } & \multicolumn{2}{|c|}{ Model III } & \multicolumn{2}{|c|}{ Model IV } \\
\hline \multirow[b]{2}{*}{$\begin{array}{l}\text { Number of post-secondary } \\
\text { educated grandfathers } \\
\text { (ref: } 0 \text { ) }\end{array}$} & Coefficient & $95 \% \mathrm{CI}$ & Coefficient & $95 \%$ CI & Coefficient & $95 \% \mathrm{CI}$ & Coefficient & $95 \% \mathrm{CI}$ \\
\hline & & & & & & & & \\
\hline 1 & $0.18 * * *$ & $0.15-0.20$ & $0.07 * * *$ & 0.05-0.09 & $0.03^{* *}$ & $0.01-0.05$ & $0.03 * *$ & $0.01-0.05$ \\
\hline 2 & $0.28 * * *$ & $0.25-0.32$ & $0.13^{* * *}$ & $0.09-0.16$ & $0.07 * * *$ & $0.04-0.11$ & $0.06 * *$ & $0.03-0.10$ \\
\hline $\begin{array}{l}\text { Father's education } \\
\text { (ref: up to primary) }\end{array}$ & & & & & & & & \\
\hline Lower secondary & & & $0.09 * * *$ & $0.07-0.12$ & $0.06 * * *$ & $0.03-0.08$ & $0.05^{* * *}$ & $0.03-0.08$ \\
\hline Higher secondary & & & 0.20 *** & $0.18-0.22$ & $0.13^{* * *}$ & $0.11-0.15$ & $0.12 * * *$ & $0.10-0.15$ \\
\hline Post-secondary & & & $0.42^{* * *}$ & $0.40-0.45$ & $0.31 * * *$ & $0.28-0.33$ & $0.29 * * *$ & $0.26-0.31$ \\
\hline $\begin{array}{l}\text { Mother's education } \\
\text { (ref: up to primary) }\end{array}$ & & & & & & & & \\
\hline Lower secondary & & & & & $0.07 * * *$ & $0.05-0.10$ & $0.07 * * *$ & $0.05-0.09$ \\
\hline Higher secondary & & & & & $0.15^{* * *}$ & $0.13-0.17$ & $0.14 * * *$ & $0.12-0.16$ \\
\hline Post-secondary & & & & & $0.27 * * *$ & $0.25-0.30$ & $0.26^{* * *}$ & $0.23-0.28$ \\
\hline $\begin{array}{l}\text { Household net wealth } \\
\text { (standardised by country) }\end{array}$ & & & & & & & $0.04^{* * *}$ & 0.03-0.05 \\
\hline
\end{tabular}

All models adjust for child gender and child year of birth; fixed effect for country and random effect for family.

$\mathrm{N}=35,280$ children in 16,129 families

$* * * \mathrm{p}<0.000 * * \mathrm{p}<0.01$ 


\section{Primary models}

Is there an association between grandparental education and grandchildren's education, independent of parent's education? Table 4 provides the coefficients and confidence intervals from linear probability models; point estimates are interpreted as the probability of G3 attaining a tertiary education. We present four models with increasing information about G2 added to each subsequent model. In our first analysis we regressed grandchild tertiary education on the number of grandfathers with a post-secondary education, controlling for the number of G3 siblings, child's gender and year of birth. Having one grandfather with a post-secondary education is associated with an 18\% higher probability, compared to having no post-secondary educated grandfathers, while having both post-secondary educated grandfathers improved the probability by 28\%. This pattern remains when we include the education of the father in model II; although the coefficients now drop to $7 \%$ and $13 \%$ respectively. When we include mother's education, we still observe a weaker, but nonetheless statistically significant, association between G1 and G3 education (3\% and $7 \%)$.

Finally, in model IV, we adjusted for parental household net wealth; while this variable was associated with a $4 \%$ increase in the probability of the child's attaining a tertiary education, it only very slightly altered the findings on the association of either the parents' or the grandfathers' education with child education. As expected, we also find evidence for independent, positive, and substantial associations between both the mother's and the father's education and child education. The association with father's post-secondary education is slightly stronger than with the mother's post-secondary education but the difference is not statistically significant (Wald test: $F=1.83$, $\mathrm{p}=0.176)$.

\section{Moderators}

Next we questioned to what extent the association between grandparental education and grandchildren's educational outcomes is moderated by 1) lifespan overlap, 2) family size, and 3) educational level of the parents. Figures 1 and 2 show the interactions plotted out, and supplementary tables S7-S9 show the point estimates for all the models with interactions.

We found no support for the notion that the association between grandparental education and grandchild's education is stronger when grandparents' lifespan overlaps with the grandchild's 
school years (figure 1). For none of the three cut-offs, 5, 10 or 16 years, do we find any significant interaction effects. Most children's grandfathers were alive until they reached age 5 (68\% and $74 \%$ for the paternal and maternal grandfather respectively), and $73 \%$ and $80 \%$ (respectively) of children up to age 16. This low variation may explain why we do not find any significant results. The full distributions for all overlap variables are shown in the supplementary table S10.
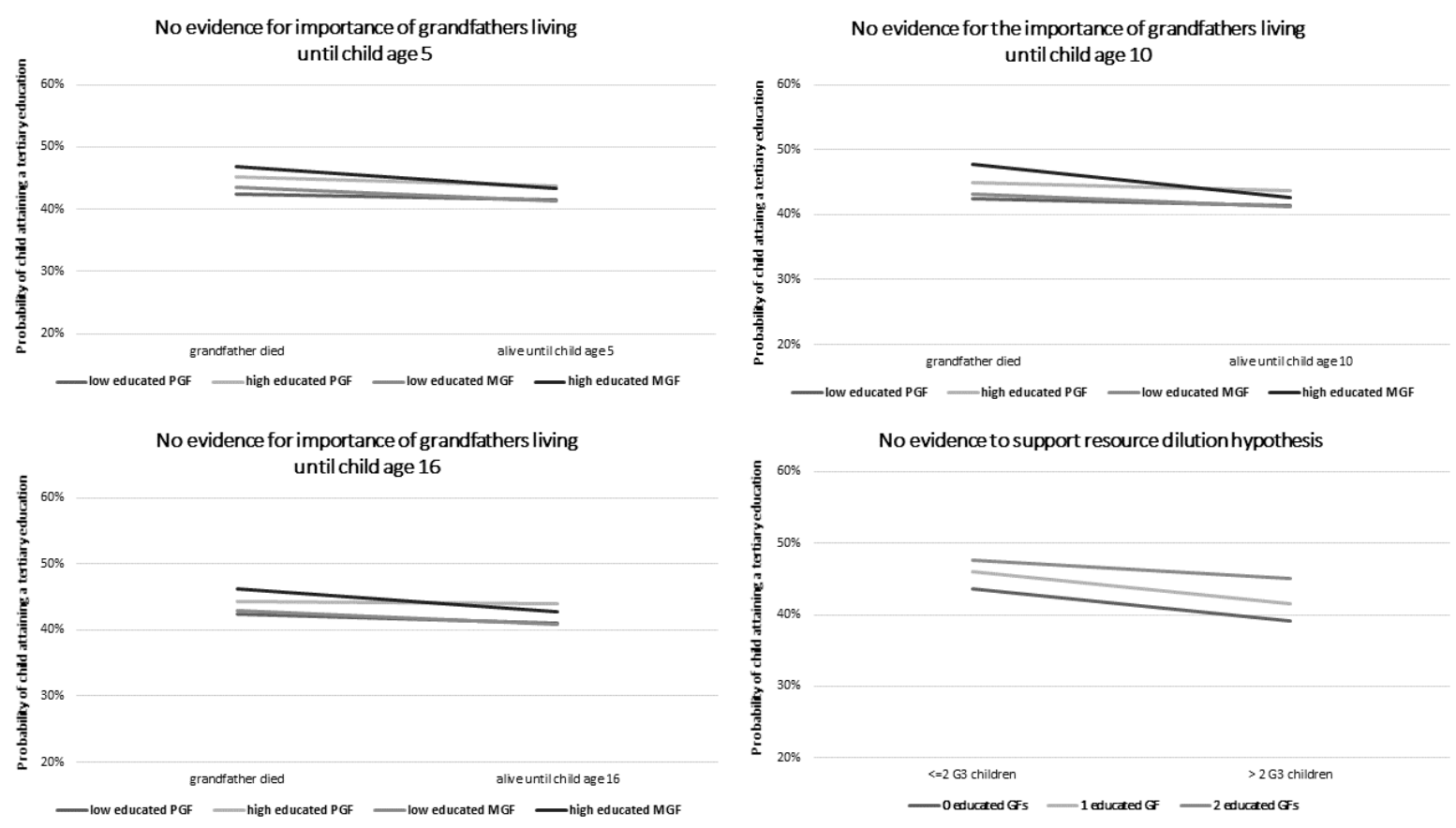

Figure 1: interaction plots for grandfathers being alive until child ages 5, 10, and 16 (note that grandfathers here are modelled individually), and an interaction plot for the number of grandfathers by the number of the grandchild's siblings.

We do not find evidence that the G1-G3 association in education is different for grandchildren with from small families (where the child is an only child or has only one sibling) compared to grandchildren with 2 or more siblings (figure 1). As a robustness test, we also recoded family size as having zero, 1, 2, or 3+ siblings, but again we find no significant differences. Nor did we find evidence for interactions between the father or mother being an only child and the respective grandfather's education, and all the coefficients were close to zero (figure 2 and Supplementary table S7). Finally, we also found no support for the idea that the impact of grandfathers' education is conditional on parental education (figure 2). The signs for the interaction terms (table S8) do suggest that the positive effect of grandfather's education is strongest among grandchildren of the lowest educated parents, but the interactions are not statistically significant. 

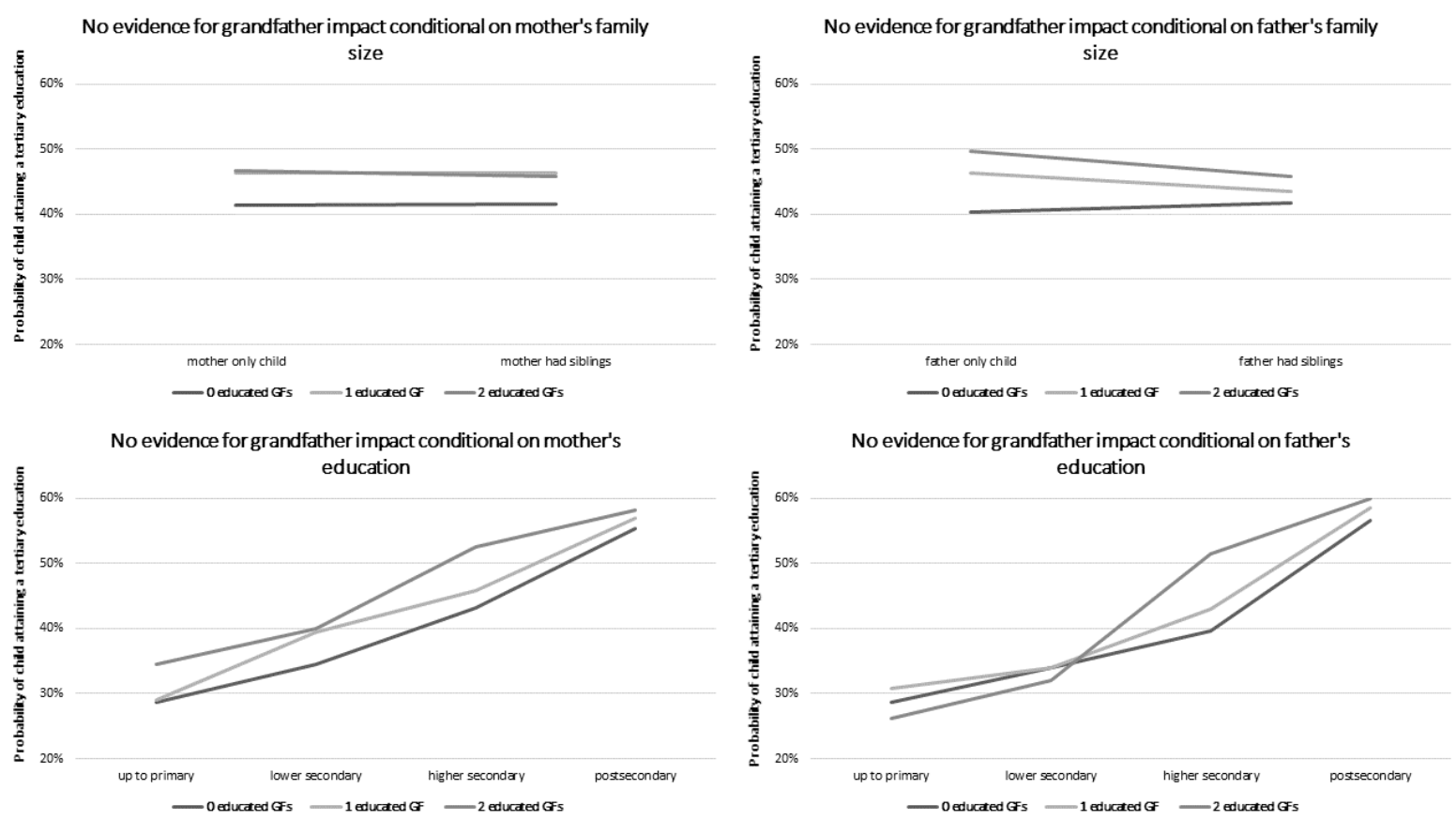

Figure 2: interaction plots for the number of educated grandfathers, conditional on each parent being an only child and each parent's education.

\section{Heterogeneity at the country level}

In the analyses above, we pooled data across countries because we wanted to have maximal statistical power when comparing different operationalisations of grandparent education. SHARE data permitted us a rare opportunity to make such comparisons as it provides information on all four grandparents and both parents. Furthermore, the pooled sample gave us more power to test interactions that might be universal across societies. We refrain from testing hypotheses about specific country differences. We argue that there no convincing theoretical or empirical grounds to formulate such hypotheses. A recent review of 60 empirical analyses of the effect of grandparental education on children's educational outcomes did not find any clear pattern of country differences (Anderson et al. 2018). Nevertheless, we briefly present and discuss analyses by country, because heterogeneity in associations across countries - whether for substantive or sampling reasons - may partly drive the mixed results in this literature. This field of inquiry is in a relatively early stage, and adding more empirical detail may also help in the development of theoretical arguments. 
The only consistent finding across countries is that where there is a significant association it almost always involves one or both grandfathers. This reflects what we find in our pooled analysis. Another striking observation when looking at both the fit statistics for different operationalisations of G1 education and the summary substantive findings across countries is the lack of any clear geographical patterns. In six out of fifteen countries, the best fitting model was that with the average of all grandparents' education, although only in four of these were there any significant associations, and in Slovenia the fit was better for the averages split by grandparent gender. For Austria and Sweden, a single dominant grandparent fit the data best and in Belgium, the best fit was for grandparents split by gender. Spain stands alone with the maternal grandfather only providing the best model fit. The best fitting model is not always the model with statistically significant 'grandparent effects'; in Israel the paternal grandfather is the best fitting model while the only significant association is that with maternal and paternal post-secondary-educated grandparents. In the Netherlands, we found no evidence at all for an association between grandparent and grandchild education, regardless of how grandparent education was modelled. In Belgium and Israel only a single operationalisation of grandparent education was significant, while in France, Switzerland and Italy, model choice does not make much difference; in most models we found a significant association.

Figure 3 shows the coefficients for the association with grandfathers by country and for the pooled sample. Countries are ordered by the size of the coefficient for having one post-secondary educated grandfather versus having none. Although there is quite some heterogeneity across countries, in nine cases the country-specific coefficient lies within the 95\%ci of the pooled coefficient. Only for Denmark $(\mathrm{p}=0.025)$ and Czechia $(\mathrm{p}<0.01)$ is the difference between the country-specific coefficient and the pooled coefficient significant. In eight countries the coefficient is larger than the pooled coefficient. In 11 out of 15 countries, we find a positive association, but only in three countries is the coefficient statistically significant. Again there is no obvious geographic pattern in the cross-country heterogeneity we observe.

The coefficients for having a second highly educated grandfather show even more heterogeneity. In most countries, few men in the grandfather cohorts obtained higher education and thus the chances of both grandfathers having post-secondary education are low. The resulting large 
standard errors mean that the country-specific coefficients do not differ significantly from the pooled coefficient (note that some confidence intervals are wider than the printed area of -0.20 to 0.35). Once more the country-difference in this coefficient shows no geographical pattern, nor is the size of this coefficient related to first one (correlation between the two coefficients is 0.07 ). We find larger coefficients for one grandfather in larger samples $(\mathrm{r}=0.35)$ but not for the second grandfather ( $r=0.07$; also see figures S1 and S2 in the supplement).
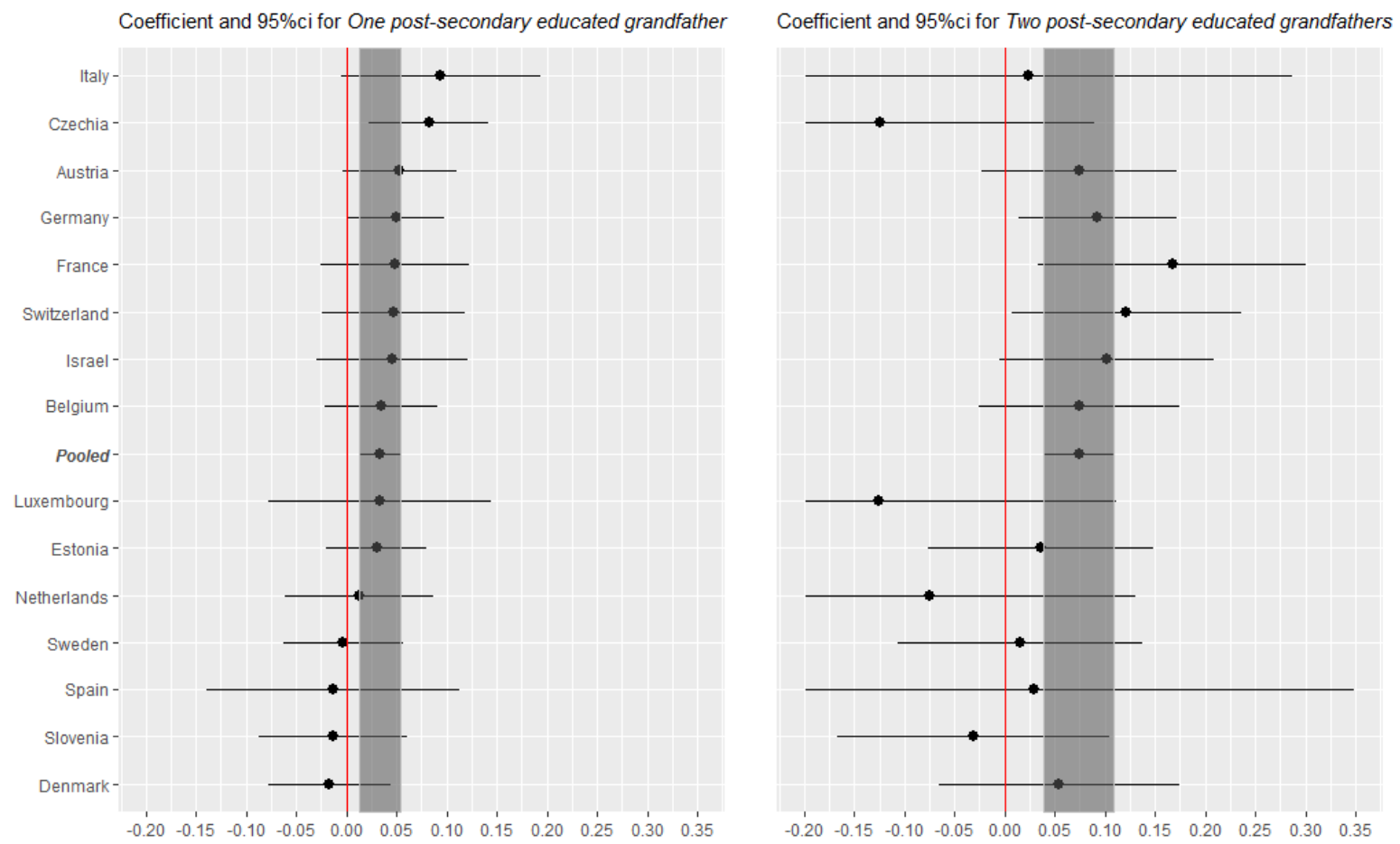

\section{Discussion}

What new insights does this study add to our understanding of grandparental 'effects'? First, we showed the importance of who of four possible grandparents are included in the measurement of "grandparental education”. A comparison of fourteen different models for G1 educational attainment suggested that taking into account both grandfathers, but not grandmothers, give the best fit. Most previous studies did not or were not able to take into account both grandfathers, however, nor could they include grandmothers. 
The importance of grandfathers was clear in our pooled analysis, but when we ran our exploratory models separately for each country, we observed more mixed results (figure 3). The main reason for our pooled analysis was to increase statistical power. The mixed results by country may well reflect low power and sample variation. This may also be part of the explanation for the mixed findings in the literature, where sample sizes often are limited. Moreover, the operationalisation of grandparental education is often data-driven (i.e. only information on one lineage is available) and different operationalisations lead to different findings. Of course, there may also be genuine context-specific associations. We recommend that future studies are not only clear about conceptual and methodological reasons for the operationalisation of grandparental education, but that they also provide sufficient sensitivity analyses to allow further comparisons with other studies (preferably including replications of previous approaches).

\section{Two grandfathers}

We now turn to our main substantive finding of the additional benefit of having one or two grandfathers with post-secondary education net of parental education and household wealth. In other words, there is evidence for a non-Markovian intergenerational transmission of education. That this association remains after controlling for G2 wealth which may perhaps count against the material mechanisms argument, although we cannot be sure as we do not have information on G1 wealth. This may instead be interpreted as support for cultural mechanisms, such as an educationorientated family climate, which would be important to directly measure in future research.

It is particularly noteworthy that both maternal and paternal grandfathers' education is associated with the grandchild's attainment. That the probability of attaining tertiary education increases as the number of educated grandfathers increases suggests that there is a cumulative advantage of first generation education; each grandparental lineage appears to provide some added benefit. As far as we are aware, this is this first study to report such a result for educational attainment. This finding may reflect the ability of elites to preserve their position - only 3.5\% of grandchildren have two higher educated grandfathers. Alternatively, having two grandfathers might be beneficial because it increases the likelihood of close contact as having two grandfathers increases the chance of geographical proximity and good family relationships with at least one of them. Having educated grandfathers on both sides of the family provides an extra advantage in societies where 
grandparents are more dispersed. In high-income settings, it is unusual for both sets of grandparents to be in close geographical proximity to all their children and grandchildren (Chan \& Ermisch 2015). Grandchildren who spend most of their time closer to one set of grandparents are at no disadvantage if grandfathers on both sides are educated. This is especially the case where there are not strict post-marital residence traditions, so children might be closer to one or other lineage almost randomly.

\section{Grandmothers and mothers}

Although we find no evidence for associations between grandmothers' education and grandchildren's attainment, our results do emphasise the importance of mothers. Much prior research ignores mothers and often only information about the father is used as an indicator of G2 education. Our results show that the exclusion of maternal education is likely to lead to overestimation of the G1-G3 association (and of the association between father's education and G3 as well). While our G1-G3 association remains significant, the inclusion of mother's education dramatically reduces the sizes of the associations of both the grandfathers and the father. This is an important finding in itself as future multigenerational research will have to take into account mothers' and grandmothers' education, given the fact that the distribution of women's education is rapidly changing (Klesment \& Van Bavel 2015). The mothers (G2) in the SHARE sample we use here are in fact today's grandmothers.

\section{Moderators and mechanisms}

What are the implications for the lack of interactions between grandparental education and sibship size or G2 education? The first, no moderation by family size, seems problematic for interpretations of the G1-G3 association based on material and direct contact mechanisms. Note that we do observe the expected negative association between G3 family size and educational outcomes; children from families with three children or more children have lower chances of attaining higher education. It is possible that grandparents do not equally distribute their resources among grandchildren; perhaps they differentiate based on need. If this were the case, we would expect to find evidence for grandfathers biasing resources towards grandchildren whose parents were less educated but we do not find this either. 
Our finding that grandfathers' education is equally strongly associated with grandchild education irrespective of the lifespan overlap between grandfather and grandchild can be interpreted as suggesting that grandfathers do not need to have direct contact with grandchildren in order to make a difference. There are explanations for a grandparent effect, independent of parental resources, that does not require contact, but equally one can interpret this finding as support for the notion that grandfathers' education operates through the parents, but is simply not measured accurately enough, and future research should try to identify and test potential mechanisms to uncover how this relationship operates.

\section{Sample limitations}

Two issues about our sample should be kept in mind when interpreting our findings. First, our study is, by design, limited to intact two parent heterosexual families because we wanted to rely on full information on both parents and all four grandparents. Our conclusions cannot be generalised to other types of families, and it may well be the case that the role of grandparents is different in single-parent families (see for instance the argument about grandparents as substitute parents in Bol and Kalmijn (2016)). We have pooled samples from fifteen countries to gain statistical power; each separate sample may be too small to produce meaningful results. We account for differences in relative sample size by weighting relative to each country's population size, but our findings cannot be generalised to other settings beyond this group of countries.

\section{Conclusion}

In the absence of consistent conclusions from recent work examining multi-generational reproduction of education, we conducted a large cross-national analysis of grandparental associations with grandchild education, independent of parental education. We were able to exploit data that provided information from all four grandparents and both parents which allowed us to systematically test for differences in grandparental lineages and grandparent gender. This is the first study to compare different operationalisations of 'grandparental education'. We found that having higher educated grandfathers was associated with increased probability of children's attaining a university degree, and that this is cumulative: if both grandfathers are educated the chances are even higher. These results hold after controlling for both parents' education and their net wealth, implying a non-Markovian process. However, we found no evidence for interactions 
with parental education, overlapping lifespans, or family size. Lack of support for the interaction with lifespan overlap in particular can be interpreted as support for a Markovian process, but this is less clear-cut for the other two interactions. Future research needs to further define and test plausible mechanisms operating between both G1 and G3, and between G2 and G3, to be able to make more definitive claims about the nature of multigenerational associations. Examining specific mechanisms warrants further investigation, possibly with data that trades off a large sample size with detailed information across three generations on a specific mechanism. 


\section{References}

Anderson, L., Sheppard, P. \& Monden, C., 2018. Grandparent effects in educational outcomes: a systematic review. Sociological Science.

Angrist, J., Lavy, V. \& Schlosser, A., 2010. Multiple Experiments for the Causal Link between the Quantity and Quality of Children. Journal of Labor Economics, 28(4), pp.773-824.

Black, S., Devereux, P. \& Salvanes, K., 2005. The more the merrier? The effect of family size and birth order on children's education. The Quarterly Journal of Economics, (May), pp.669700.

Blake, J., 1986. Number of siblings, family background, and the process of educational attainment. Social Biology, 33(1-2), pp.5-21.

Bol, T. \& Kalmijn, M., 2016. Grandparents’ resources and grandchildren’s schooling: Does grandparental involvement moderate the grandparent effect? Social Science Research, 55, pp.155-170.

Börsch-Supan, A. et al., 2013. Data resource profile: The Survey of Health, Ageing and Retirement in Europe (SHARE). International Journal of Epidemiology, 42(4), pp.992-1001.

Braun, S. \& Stuhler, J., 2016. The transmission of inequality across multiple generations: testing recent theories with evidence from Germany. The Economic Journal, 10.1111, p.ecoj.12453.

Carr, D. et al., 2003. How Families Still Matter: A Longitudinal Study of Youth in Two Generations. Contemporary Sociology, 32(6), p.695.

Chan, T.W. \& Boliver, V., 2013. The Grandparents Effect in Social Mobility: Evidence from British Birth Cohort Studies. American Sociological Review, 78(4), pp.662-678.

Chan, T.W. \& Ermisch, J., 2015. Residential proximity of parents and their adult offspring in the United Kingdom, 2009-10. Population Studies, 69(3), pp.355-372.

Chiang, Y.L. \& Park, H., 2015. Do grandparents matter? A multigenerational perspective on educational attainment in Taiwan. Social Science Research, 51, pp.163-173.

Choi, S. et al., 2017. Sibship Size and Educational Attainment: Evidence of Cohort Trends from 26 Low-Fertility Countries. Paper presented at the 2017 Annual Conference of the British Society for Population Studies, Liverpool, 6-8 September 2017.

Coall, D., Hilbrand, S. \& Hertwig, R., 2014. Predictors of grandparental investment decisions in contemporary europe: biological relatedness and beyond. PLoS ONE, 9(1), p.e84082. 
Deindl, C. \& Tieben, N., 2016. Resources of Grandparents: Educational Outcomes Across Three Generations in Europe and Israel. Journal of Marriage and Family.

Erola, J. \& Moisio, P., 2007. Social Mobility over Three Generations in Finland, 1959 - 2000. European Sociological Review, 23(2), pp.169-183.

Ferrie, J., Massey, C. \& Rothbaum, J., 2016. Do grandparents and great-grandparents matter? Multigenerational mobility in the US, 1910-2013, Cambridge, Mass.

Fuchs, M. \& Sixt, M., 2007. Zur nachhaltigkeit von bildungsaufstiegen. Kölner Zeitschrift für Soziologie und Sozialpsychologie, 59(1), pp.1-29.

Gibbs, B.G., Workman, J. \& Downey, D.B., 2016. The (Conditional) Resource Dilution Model: State- and Community-Level Modifications. Demography, 53(3), pp.723-748.

Hällsten, M. \& Pfeffer, F., 2016. Grand Advantage: Family Wealth and Grandchildren's Educational Achievement in Sweden,

Hellevik, O., 2009. Linear versus logistic regression when the dependent variable is a dichotomy. Quality and Quantity, 43(1), pp.59-74.

Hertel, F.R. \& Groh-Samberg, O., 2014. Class mobility across three generations in the U.S. and Germany. Research in Social Stratification and Mobility, 35, pp.35-52.

Jæger, M.M., 2012. The Extended Family and Children’s Educational Success. American Sociological Review, 77(6), pp.903-922.

Klesment, M. \& Van Bavel, J., 2015. The reversal of the gender gap in education and female breadwinners in Europe. Families and Societies Working Paper Series, 26(320116), p.37.

Knigge, A., 2016. Beyond the Parental Generation: The Influence of Grandfathers and Greatgrandfathers on Status Attainment. Demography, pp.1-26.

Lindahl, M. et al., 2015. Long- Term Intergenerational Persistence of Human Capital An Empirical Analysis of Four Generations. Journal of Human Resources, 50(1), pp.1-33.

Lindahl, M. et al., 2012. Long-Term Intergenerational Persistence of Human Capital: An Empirical Analysis of Four Generations. Journal of Human Resources, 50(1), pp.1-33.

Mare, R.D., 2011. A multigenerational view of inequality. Demography, 48(1), pp.1-23.

Mare, R.D., 2014. Multigenerational aspects of social stratification: Issues for further research. Research in Social Stratification and Mobility, 35.

Modin, B., Erikson, R. \& Vågerö, D., 2013. Intergenerational continuity in school performance: Do grandparents matter? European Sociological Review, 29(4), pp.858-870. 
Møllegaard, S. \& Jæger, M.M., 2015. The effect of grandparents’ economic, cultural, and social capital on grandchildren's educational success. Research in Social Stratification and Mobility, 42, pp.11-19.

Mood, C., 2010. Logistic regression: Why we cannot do what We think we can do, and what we can do about it. European Sociological Review, 26(1), pp.67-82.

Pfeffer, F.T., 2014. Multigenerational approaches to social mobility. A multifaceted research agenda. Research in Social Stratification and Mobility, 35, pp.1-12.

Sear, R., Mace, R. \& McGregor, I., 2000. Maternal grandmothers improve nutritional status and survival of children in rural Gambia. Proceedings of the Royal Society B-Biological Sciences, 267(1453), pp.1641-7.

SHARE, 2015. Release Guide 1.0.0:Wave 5, Available at: http://www.share-project.org/datadocumentation/release-guides.html.

Steelman, L.C. et al., 2002. Reconsidering the effects of sibling configuration: Recent Advances and Challenges. Annual Review of Sociology, 28(1), pp.243-269.

UNESCO, 2013. The International Standard Classification of Education 2011,

Warren, J. \& Hauser, R., 1997. Social Stratification across Three Generations: New Evidence from the Wisconsin Longitudinal Study. American Sociological Review, 62(4), pp.561-572.

Wightman, P. \& Danziger, S., 2014. Multi-generational income disadvantage and the educational attainment of young adults. Research in Social Stratification and Mobility, 35, pp.53-69.

Wolbers, M.H.J. \& Ultee, W.C., 2013. Driegeneraties- en tweeoudersvragen over het opleidingsniveau van mannen en vrouwen in Nederland. Mens \& Maatschappij, 88(3), pp.276-294.

Ziefle, A., 2016. Persistent Educational Advantage Across Three Generations: Empirical Evidence for Germany. Sociological Science, 3, pp.1077-1102. 


\section{Supplements}

Table S1: Distribution of main variables in couples (G2) with two responding partners and couples with one nonresponding partner.

\begin{tabular}{|c|c|c|c|}
\hline & & $\begin{array}{l}\text { Two responding } \\
\text { partners }\end{array}$ & $\begin{array}{l}\text { One non- } \\
\text { responding } \\
\text { partner }\end{array}$ \\
\hline \multicolumn{4}{|l|}{ Total } \\
\hline \multirow{9}{*}{ Men } & $\mathrm{N}$ & 21,328 & 4,783 \\
\hline & $\%$ post-secondary educated & 29 & 35 \\
\hline & $\%$ married & 92 & 87 \\
\hline & $\%$ widowed & 1 & 1 \\
\hline & $\%$ divorced & 3 & 5 \\
\hline & $\%$ never married & 2 & 3 \\
\hline & Mean (sd) number of children & $2.4(1.4)$ & $2.3(1.38)$ \\
\hline & $\%$ post-secondary educated mother & 5 & 6 \\
\hline & $\%$ post-secondary educated father & 11 & 13 \\
\hline \multirow[t]{9}{*}{ Women } & $\mathrm{N}$ & 21,328 & 6,241 \\
\hline & \% post-secondary educated & 27 & 29 \\
\hline & $\%$ married & 93 & 87 \\
\hline & $\%$ widowed & 1 & 3 \\
\hline & $\%$ divorced & 3 & 4 \\
\hline & $\%$ never married & 2 & 2 \\
\hline & Mean (sd) number of children & $2.4(1.36)$ & $2.4(1.4)$ \\
\hline & $\%$ post-secondary educated mother & 6 & 7 \\
\hline & $\%$ post-secondary educated father & 11 & 13 \\
\hline
\end{tabular}

Marital status is taken from the first interview wave

Denominator $=$ valid responses 
Table S2: Sample selection process

\begin{tabular}{|l|l|l|l|}
\hline Selection & $\begin{array}{l}\text { G2 } \\
\text { individuals }\end{array}$ & $\begin{array}{l}\text { G2 } \\
\text { couples }\end{array}$ & G3 cases \\
\hline Respondents interviewed in waves 5 or 6 (15 countries) & 75,996 & & \\
Minus 7,171 cases with missing information on G1 education & 68,925 & & \\
Minus 127 newly-formed couples since first surveyed & 68,698 & & \\
Minus 11,024 who had non-responding partners & 57,674 & & \\
Minus 14,938 who were never a couple in SHARE & 42,736 & & \\
Minus 40 same-sex couples & 42,656 & & \\
Full information couples and children: & & 21,328 & 55,333 \\
Minus 9,504 mismatched children (year of birth \& sex) & & & 45,829 \\
Minus 10 implausible child years of birth & & & 45,819 \\
Minus 9,316 under-23-year-olds \& missing data on education & & $\mathbf{1 6 , 1 2 9}$ & $\mathbf{3 5 , 2 8 0}$ \\
Minus 1223 children with missing data on 7 other variables & & & \\
\hline
\end{tabular}

Table S3: ISCED conversion scheme

\begin{tabular}{|l|l|l|}
\hline $\begin{array}{l}\text { ISCED 1997 } \\
\text { scale }\end{array}$ & Brief description & $\begin{array}{l}\text { Conversion to 4 } \\
\text { levels }\end{array}$ \\
\hline Level & & Level \\
\hline 0 & None & 0 \\
\hline 1 & Primary & \\
\hline 2 & Lower secondary & 1 \\
\hline 3 & Upper secondary & 2 \\
\hline 4 & Post-secondary, non-tertiary & \multirow{2}{*}{3} \\
\hline 5 & Tertiary & \\
\hline 6 & Doctoral or equivalent & \\
\hline
\end{tabular}

Source: http://ec.europa.eu/eurostat/documents/1978984/6037342/Comparability_ISCED_2011_ISCED_1997.pdf

In our main analyses we coded education in four categories: none and primary education; lower secondary; upper secondary; and any post-secondary education. For model robustness tests and to compute z-scores, we use the 1997 ISCED scale.

Table S4: Results from linear probability models regressing child tertiary education on G1 and G2 education with G1 and $G 2$ education as a binary variable for post-secondary education or higher ( $1=y e s, 0=$ less than post-secondary education).

\begin{tabular}{|l|l|l|l|l|}
\hline & Model I & Model II & Model III & Model IV \\
\hline \multirow{3}{*}{ Paternal grandfather } & Coef. (95\% CI) & Coef. (95\% CI) & Coef. (95\% CI) & Coef. (95\% CI) \\
& $0.17^{* * *}(0.14-$ & $0.06^{* * *}(0.04-$ & $0.04^{* * *}(0.02-$ & $0.04^{* *}(0.01-0.06)$ \\
Maternal grandfather & $.019)$ & $0.09)$ & $0.07)$ & \\
& $0.15^{* * *}(0.12-$ & $0.08^{* * *}(0.06-$ & $0.04^{* * *}(0.02-$ & $0.03^{* *}(0.01-0.06)$ \\
Father & $0.17)$ & $0.10)$ & $0.06)$ & \\
& & $0.29^{* * *}(0.27-$ & $0.23^{* * *}(0.22-$ & $0.22^{* * *}(0.20-$ \\
Mother & & $0.30)$ & $0.25)$ & $0.23)$ \\
HH net wealth & & $0.18^{* * *}(0.16-$ & $0.17^{* * *}(0.15-$ \\
& & & $0.20)$ & $0.19)$ \\
& & & & $0.05^{* * *}(0.04-$ \\
& & & $0.06)$ \\
\hline
\end{tabular}

Models control for child year of birth and gender, and include a random effect for family and fixed effect for country. $\mathrm{N}=35,280$ children in 16,129 families ${ }^{* * *} \mathrm{p}<0.000{ }^{* *} \mathrm{p}<0.01$ 
Table S5: Results from OLS models regressing G3 education on G1 and G2 education with education measured as country-standardised z-scores based on ISCED 1997 levels.

\begin{tabular}{|l|l|l|l|l|}
\hline & Model I & Model II & Model III & Model IV \\
\hline \multirow{3}{*}{ Paternal grandfather } & Coef. (95\% CI) & Coef. (95\% CI) & Coef. (95\% CI) & Coef. (95\% CI) \\
& $0.13^{* * *}(0.12-$ & $0.05^{* * *}(0.03-$ & $0.03^{* * *}(0.01-$ & $0.02^{* *}(0.01-0.04)$ \\
Maternal grandfather & $0.15)$ & $0.06)$ & $0.04)$ & \\
& $0.13^{* * *}(0.11-$ & $0.07^{* * *}(0.05-$ & $0.02^{* *}(0.01-0.04)$ & $0.02^{*}(0.01-0.03)$ \\
Father & $0.14)$ & $0.08)$ & & \\
& & $0.29^{* * *}(0.28-$ & $0.22^{* * *}(0.21-$ & $0.21^{* * *}(0.19-$ \\
Mother & & & $0.24)$ & $0.23)$ \\
& & & $0.19^{* * *}(0.18-$ & $0.19^{* * *}(0.17-$ \\
HH net wealth & & $0.21)$ & $0.20)$ \\
& & & & $0.09^{* * *}(0.07-$ \\
& & & & $0.11)$
\end{tabular}

Models control for child year of birth, family size (G3), child gender, and include a random effect for family and fixed effect for country.

$\mathrm{N}=35,280$ children in 16,129 families

$* * * \mathrm{p}<0.000 * * \mathrm{p}<0.01 * \mathrm{p}<0.05$

Table S6: AIC scores and summarised main effects of grandparental education for ten exploratory models using zscores for education, presented in ascending order of AIC scores (fewer models as 'numbers of grandparents' models do not make sense in terms of z-scores)

\begin{tabular}{|l|l|l|l|}
\hline Model & Operationalisation of grandparent education & AIC & $\begin{array}{l}\text { Significant G1 - G3 } \\
\text { association?* }\end{array}$ \\
\hline l & Average of all grandparental education & 83250.72 & Yes \\
$\mathrm{m}$ & Maternal average and paternal average & 83252.44 & Yes \\
$\mathrm{n}$ & Grandfather average and grandmother average & 83252.54 & Yes \\
$\mathrm{g}$ & Dominant grandfather and dominant grandmother & 83255.52 & Yes \\
$\mathrm{f}$ & Dominant maternal and paternal grandparents & 83256.06 & Yes \\
a & All four individual grandparents & 83256.2 & Three GPs \\
$\mathrm{b}$ & Both grandfathers individually & 83259.18 & Yes, both \\
$\mathrm{e}$ & Single dominant grandparent & 83259.35 & Yes \\
c & Paternal grandfather only & 83267.49 & Yes \\
d & Maternal grandfather only & 83270.53 & Yes \\
\hline
\end{tabular}

*all positive associations

All models control for both parent's education, grandchild age and gender, with a country fixed effect $N=35,280$ children (16,129 families) 
Table S7: Estimates from linear probability models for models with grandfather education interacted with family size (G2 and G3)

\begin{tabular}{|c|c|c|c|c|c|c|c|c|}
\hline & \multicolumn{2}{|c|}{ Model VI } & \multicolumn{2}{|c|}{ Model VII } & \multicolumn{2}{|c|}{ Model VIII } & \multicolumn{2}{|c|}{ Model IX } \\
\hline & Coefficient & $95 \% \mathrm{CI}$ & Coefficient & $95 \% \mathrm{CI}$ & Coefficient & $95 \% \mathrm{CI}$ & Coefficient & $95 \% \mathrm{CI}$ \\
\hline $\begin{array}{l}\text { Number of post-secondary } \\
\text { educated grandfathers } \\
\text { (ref: 0) }\end{array}$ & & & & & & & & \\
\hline 1 & $0.02 *$ & $0.01-0.05$ & $0.03 *$ & $0.01-0.05$ & $0.02 *$ & $0.03-0.06$ & 0.02 & $-0.04-0.09$ \\
\hline 2 & $0.06 * *$ & $0.02-0.10$ & $0.06 * *$ & $0.03-0.10$ & $0.07 * *$ & $0.02-0.12$ & 0.07 & $-0.05-0.18$ \\
\hline $\begin{array}{l}\text { Father (G2) was only child } \\
\text { \#GFs educ x Father-onlv: }\end{array}$ & -0.01 & $-0.04-0.02$ & & & & & & \\
\hline 1 & 0.03 & $-0.03-0.09$ & & & & & & \\
\hline 2 & -0.01 & $-0.10-0.09$ & & & & & & \\
\hline $\begin{array}{l}\text { Mother (G2) was only child } \\
\text { \#GFs educ x Mother-only: }\end{array}$ & & & 0.01 & $-0.02-0.04$ & & & & \\
\hline $1 \mathrm{x} 1$ & & & -0.01 & $-0.07-0.07$ & & & & \\
\hline $2 \times 1$ & & & -0.02 & $-0.12-0.09$ & & & & \\
\hline G3 small family ( $<2$ sibs) & & & & & $0.04^{* * *}$ & $0.03-0.06$ & & \\
\hline \#GFs educ $x$ small G3 fam & & & & & & & & \\
\hline 1 & & & & & -0.01 & $-0.04-0.03$ & & \\
\hline 2 & & & & & -0.01 & $-0.07-0.03$ & & \\
\hline Child sibship size ( $0=$ ref) & & & & & & & & \\
\hline 1 sibling & & & & & & & -0.01 & $-0.04-0.01$ \\
\hline 2 siblings & & & & & & & -0.02 & $-0.05-0.01$ \\
\hline $3+$ siblings & & & & & & & $-0.08 * * *$ & $-0.11--0.06$ \\
\hline \#GFs educ x sibship size & & & & & & & & \\
\hline $1 \times 1$ sibling & & & & & & & 0.01 & $-0.06-0.07$ \\
\hline $1 \times 2$ siblings & & & & & & & 0.01 & $-0.06-0.08$ \\
\hline $1 \times 3+$ siblings & & & & & & & -0.01 & $-0.07-0.07$ \\
\hline $2 \times 1$ sibling & & & & & & & -0.01 & $-0.14-0.12$ \\
\hline $2 \times 2$ siblings & & & & & & & -0.03 & $-0.10-0.10$ \\
\hline $2 \times 3+$ siblings & & & & & & & 0.05 & $-0.09-0.18$ \\
\hline
\end{tabular}

Note that numbers of siblings are the siblings of the grandchild (e.g. siblings $=0$ means the child is an only child)

$\mathrm{N}=35,280$ children in 16,129 families

*** $<<0.000 * * \mathrm{p}<0.01 * \mathrm{p}<0.05$ 
Table S8: Estimates from linear probability models with grandfather education interacted with G2 education

\begin{tabular}{|c|c|c|c|c|}
\hline & \multicolumn{2}{|c|}{ Model X } & \multicolumn{2}{|c|}{ Model XI } \\
\hline & Coefficient & $95 \% \mathrm{CI}$ & Coefficient & $95 \% \mathrm{CI}$ \\
\hline $\begin{array}{l}\text { Number of post-secondary } \\
\text { educated grandfathers } \\
\text { (ref: } 0 \text { ) }\end{array}$ & & & & \\
\hline 1 & 0.08 & $-0.01-0.17$ & -0.02 & $-0.05-0.10$ \\
\hline 2 & 0.08 & $-0.02-0.17$ & 0.04 & $-0.07-0.14$ \\
\hline $\begin{array}{l}\text { Father's education } \\
\text { (ref: up to primary) }\end{array}$ & & & & \\
\hline Lower secondary & $0.06 * * *$ & $0.03-0.08$ & & \\
\hline Higher secondary & $0.12 * * *$ & $0.10-0.15$ & & \\
\hline Post-secondary & $0.29 * * *$ & $0.27-0.32$ & & \\
\hline 1 GF $x$ Father low-sec & -0.08 & $-0.19-0.03$ & & \\
\hline 1 GF x Father high-sec & -0.05 & $-0.15-0.04$ & & \\
\hline 1 GF x Father post-sec & -0.05 & $-0.15-0.04$ & & \\
\hline 2 GFs x Father low-sec & -0.14 & $-0.32-0.03$ & & \\
\hline 2 GFs $x$ Father high-sec & 0.06 & $-0.07-0.18$ & & \\
\hline 2 GFs x Father post-sec & -0.03 & $-0.13-0.07$ & & \\
\hline $\begin{array}{l}\text { Mother's education } \\
\text { (ref: up to primary) }\end{array}$ & & & & \\
\hline Lower secondary & & & $0.07 * * *$ & $0.04-0.09$ \\
\hline Higher secondary & & & $0.14 * * *$ & $0.11-0.16$ \\
\hline Post-secondary & & & $0.27 * * *$ & $0.24-0.30$ \\
\hline 1 GF x Mother low-sec & & & 0.07 & $-0.03-0.17$ \\
\hline 1 GF x Mother high-sec & & & 0.01 & $-0.07-0.09$ \\
\hline 1 GF x Mother post-sec & & & -0.02 & $-0.10-0.06$ \\
\hline 2 GFs x Mother low-sec & & & 0.11 & $-0.06-0.27$ \\
\hline 2 GFs x Mother high-sec & & & 0.07 & $-0.07-0.20$ \\
\hline 2 GFs x Mother post-sec & & & -0.01 & $0.12-0.12$ \\
\hline
\end{tabular}

Models adjust for child gender, child year of birth and HH net wealth, education of the other parent; fixed country effect and random effect for family. $\mathrm{N}=35,280$ children in 16,129 families ${ }^{* * *} \mathrm{p}<0.000$ 
Table S9: Estimates from linear probability models with grandfather education interacted with overlapping lifespan of grandfathers and child up to ages 5, 10, and 16.

\begin{tabular}{|c|c|c|c|c|c|c|}
\hline & \multicolumn{2}{|c|}{ Model XII } & \multicolumn{2}{|c|}{ Model XIII } & \multicolumn{2}{|c|}{ Model XIV } \\
\hline & Coefficient & $95 \% \mathrm{CI}$ & Coefficient & $95 \% \mathrm{CI}$ & Coefficient & $95 \% \mathrm{CI}$ \\
\hline PGF post-secondary educ & 0.03 & $-0.01-0.07$ & & & & \\
\hline PGF overlap16 & -0.02 & $-0.03-0.01$ & & & & \\
\hline MGF post-secondary educ & 0.03 & $-0.01-0.07$ & & & & \\
\hline MGF overlap16 & -0.02 & $-0.03-0.01$ & & & & \\
\hline PGF post-secondary educ & & & $0.05^{*}$ & $0.01-0.08$ & & \\
\hline PGF overlap10 & & & -0.01 & $-0.02-0.01$ & & \\
\hline PGFpostsec x PGFoverlap10 & & & -0.02 & $-0.07-0.03$ & & \\
\hline MGF post-secondary educ & & & 0.03 & $-0.01-0.07$ & & \\
\hline PGF overlap5 & & & & & 0.01 & $-0.02-0.02$ \\
\hline PGFpostsec x PGFoverlap5 & & & & & -0.01 & $-0.07-0.05$ \\
\hline MGF post-secondary educ & & & & & 0.01 & $-0.05-0.06$ \\
\hline MGF overlap5 & & & & & -0.02 & $-0.04-0.01$ \\
\hline MGFpostsec x MGFoverlap5 & & & & & 0.03 & $-0.03-0.09$ \\
\hline
\end{tabular}

PGF = paternal grandfather, $\mathrm{MGF}=$ maternal grandfather

5, 10 and 16 denote the child's age until which the grandfathers' life overlapped with. Models adjust for child gender, child year of birth and household net wealth; fixed country effect and random effect for family. $\mathrm{N}=35,280$ children in 16,129 families

Table S10: proportions of children whose grandfathers were alive until their age 5, 10, and 16

\begin{tabular}{|l|l|l|}
\hline Overlapping lifespan to ages - & $\begin{array}{l}\text { Paternal } \\
\text { grandfather }\end{array}$ & $\begin{array}{l}\text { Maternal } \\
\text { grandfather }\end{array}$ \\
\hline 5 & 0.68 & 0.74 \\
10 & 0.57 & 0.64 \\
16 & 0.43 & 0.50 \\
\hline
\end{tabular}




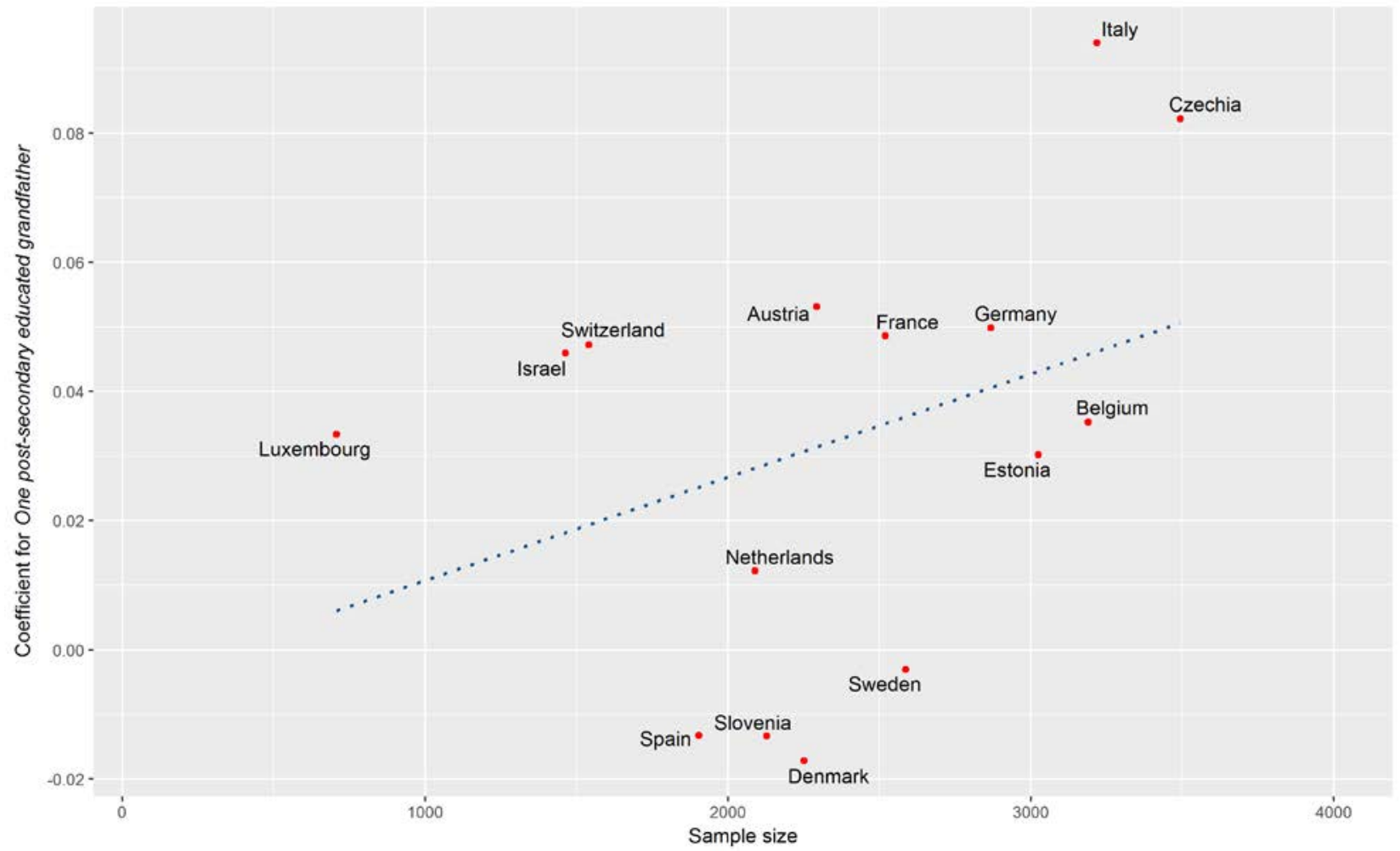

Figure S1 Scatter plot of coefficients for having one educated grandfather, by country

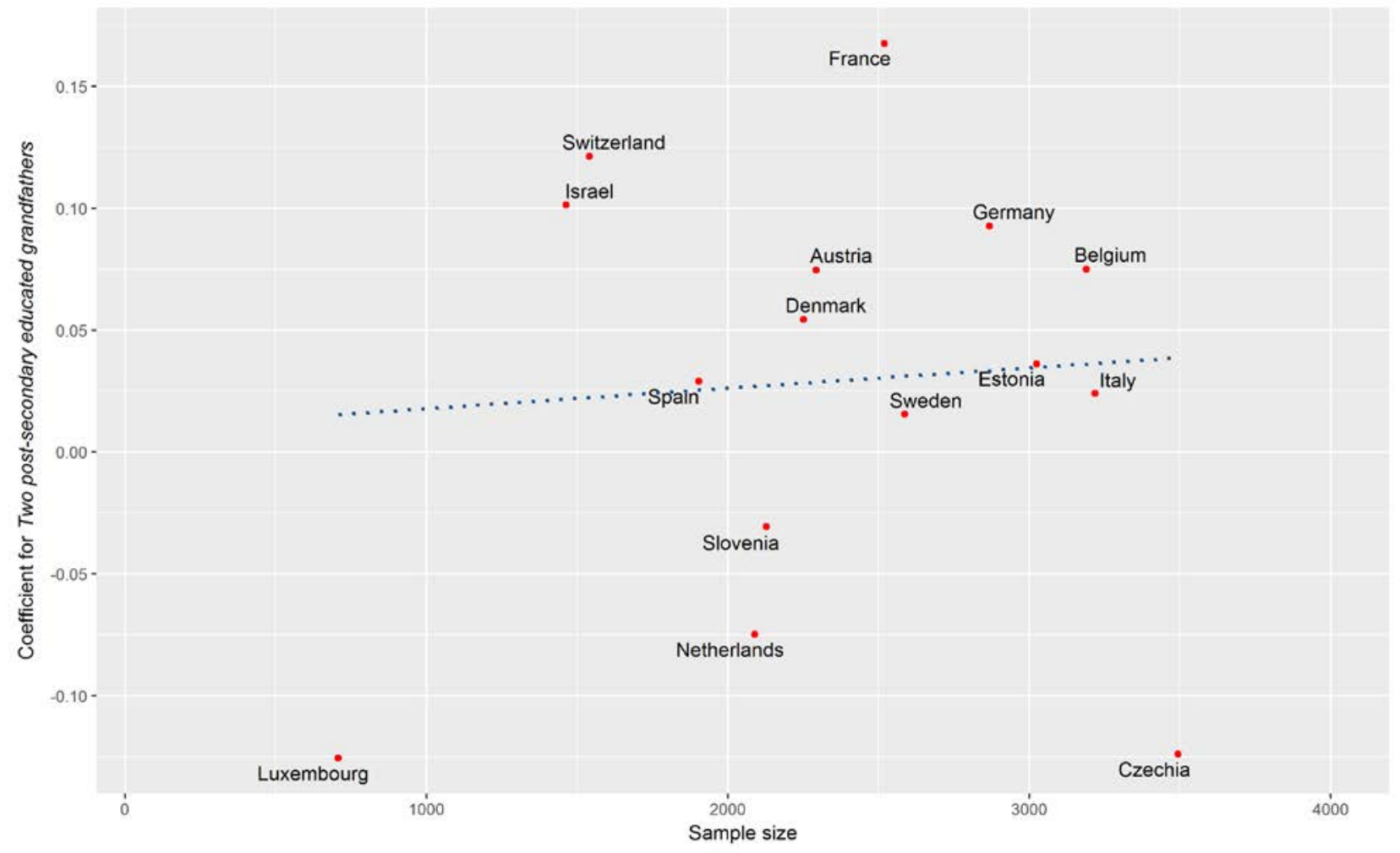

Figure S1 Scatter plot of coefficients for having two educated grandfathers, by country 